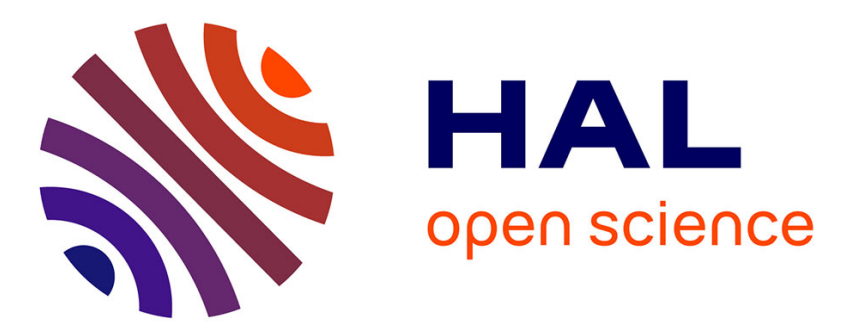

\title{
MONTE CARLO SIMULATION OF VARIABLE RANGE HOPPING AT THE FERMI LEVEL
}

\author{
G. Schönherr, H. Bässler, M. Silver
}

\section{To cite this version:}

G. Schönherr, H. Bässler, M. Silver. MONTE CARLO SIMULATION OF VARIABLE RANGE HOPPING AT THE FERMI LEVEL. Journal de Physique Colloques, 1981, 42 (C4), pp.C4-111-C4114. 10.1051/jphyscol:1981420 . jpa-00220827

\section{HAL Id: jpa-00220827 https://hal.science/jpa-00220827}

Submitted on 1 Jan 1981

HAL is a multi-disciplinary open access archive for the deposit and dissemination of scientific research documents, whether they are published or not. The documents may come from teaching and research institutions in France or abroad, or from public or private research centers.
L'archive ouverte pluridisciplinaire HAL, est destinée au dépôt et à la diffusion de documents scientifiques de niveau recherche, publiés ou non, émanant des établissements d'enseignement et de recherche français ou étrangers, des laboratoires publics ou privés. 


\title{
MONTE CARLO SIMULATION OF VARIABLE RANGE HOPPING AT THE FERMI LEVEL
}

\author{
G. Schönherr, H. Bässler and M. Silver* \\ Fachbereich Physikalische Chemie, Philipp-Universität, Hons-Meerwein-StraBe, \\ D-3550 Marburg, E.R.G. \\ * Department of Physies and Astronomy, University of North Carolina, Chapel Hizl, \\ N.C. 27514, U.S.A.
}

\begin{abstract}
Employing the Monte Carlo technique hopping at the Fermi level in a cubic lattice has been simulated as a function of temperature, electric field, hopping parameter $2 \alpha$, and time. It has been found that the predictions of the simple theories agree remarkably well with our computer experiments. In our work we find a true d.c. conductivity proportional to exp $-(\mathrm{T} / \mathrm{T})^{1 / 4}$ at low temperatures. The time dependence shows dispersion at short times due to energy relaxation and later equilibrium to the average hopping distance.
\end{abstract}

Introduction.- Perhaps the most simple, yet elegant approach to hopping at the Fermi level was the optimization approach by Mott (1) where the fameous In $\sigma \propto \mathrm{T}$-1/4 law was found. This law has since been verified (see for examples G.G.Robert et al. (2)) and now put on firm theoretical grounds by Movaghar and Schirmacher (3). While experiments (2) have shown the $\mathrm{T}^{-1 / 4}$ law the experimental data gave a conductivity which was too lange by a factor of more than $10^{4}$. Because of this discrepancy we have decided to perform a computer simulation to test these simple theoretical ideas and approximations. We have found excellent agreement between our Monte Carlo simulations and theory regarding temperature, hopping parameter, and electric field. At high temperature an activated conductivity is found and simple arguments are presented for the magnitude of the activation energy.

Computational Methods.- Because of its simplicity the Monte Carlo Method has frequently been applied to treat transport properties of disordered solids (see e.g. $(4,5))$. In the present computation a volume of $30 \times 30 \times 69$ sites with cubic symmetry (lattice parameter $a=10^{-7} \mathrm{~cm}$ ) was used employing periodic boundary conditions along $y$ and $z$ rendering the effective sample dimensions in transverse directions practically infinite. To mimic hopping at the Fermi level the distribution of the energy of the hopping sites was approximately by a half-Gaussian, $N(\varepsilon)=$

$2 \exp \left(-\varepsilon^{2} / 2 \sigma^{2}\right) /(2 \pi)^{1 / 2} a^{3} \sigma$ for $\varepsilon \geqslant 0$, the Fermi level being located at $\varepsilon=0$. We chose $\sigma=0.3 \mathrm{eV}$ which is $\gg \mathrm{kT}$ at all temperatures studied. Hopping between two sites $\mathrm{j}$ and $k$ is governed by

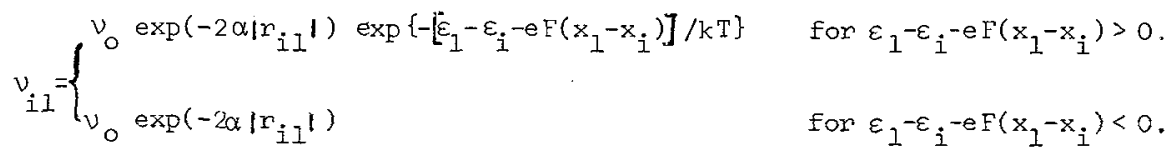

To simulate real systems we assumed $v_{0}=10^{13} \mathrm{~s}^{-1}$. For details of the simulation method see refs. $(5,6)$. 
In onder to study the energy relaxation we initially create a hopping particle at random on an arbitrary site located within the $x=1$ plane. This gives us an initial energetic non equilibrium. However, since the particle thermalize in only a few jumps, this does not distort our d.c. conductivity results. We study 20 particles per lattice configuration and average over 50 different configurations. We store $n(x, t, \varepsilon)$ where $n$ is the number of jumping particles. We thus can calculate $\langle x(t)\rangle$ and $\langle\varepsilon(t)\rangle$ from which we obtain the conductivity and the average energy. These average values are studies as a function of temperature and electric field for $2 \alpha a$ ranging fromi3 to 10 .

Results and Discussion.- Figure 1 summarizes our results for $10 g$ iovs $T^{-1 / 4}$ for various values of $2 \alpha a$ in the long time limit (thermodynamic equilibrium). At high temperatures the current is activated while at low temperature $\log i_{\infty} \propto\left(\mathrm{T}_{\mathrm{o}} / \mathrm{T}\right)^{1 / 4}$. Our $\mathrm{T}_{0}$ data are best fitted by $\mathrm{T}_{\mathrm{O}}=24 \alpha^{3} / \pi \mathrm{kN}_{\mathrm{F}}(2,3)$ where $\mathrm{N}_{\mathrm{F}}$ is the density of states at the Fermi level, in the present case $N_{F}=2 /(2 \pi)^{1 / 2} \sigma a^{3}$. Using the simple relationship derived by Mott (1) we also can derive a value of the most probable hopping distance $\langle\mathrm{R}\rangle$. Data for $\mathrm{T}=25^{\circ} \mathrm{K}$ are listed in table 1 .

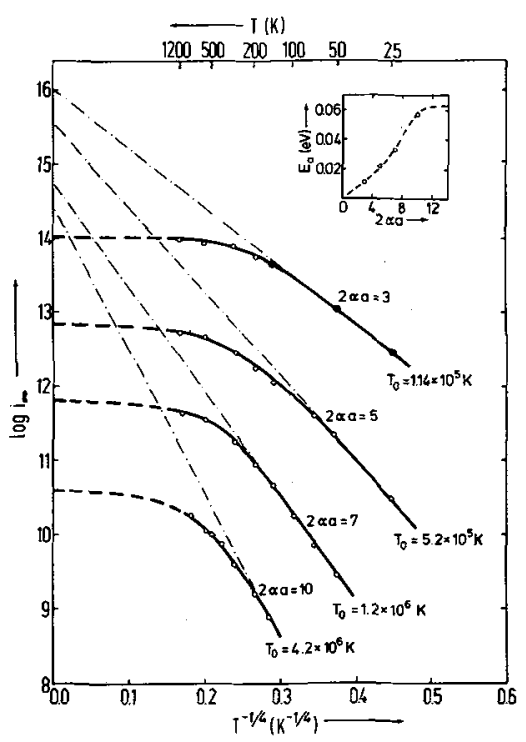

Fig. 1: $\log i_{\infty}$ vs $\mathrm{T}^{-1 / 4}$. Open circles are for a field $\mathrm{F}=10^{5} \mathrm{Vcm}^{-1}$, closed circles are corrected for the high field effect shown in fig.2. The insert shows $E_{a}$ derived from the high temperature data. The dashed line indicates $E_{a}=\left(N_{F} a_{p}^{3}\right)^{-1}$.

\begin{tabular}{c|c|c|c}
$2 \alpha a \mathrm{a}$ & $\mathrm{T}_{0}(\mathrm{~K})$ & $<\mathrm{R}>/ \mathrm{a}$ & $\mathrm{p}^{(\mathrm{T} \rightarrow \infty)}$ \\
\hline 3 & $1.1 \cdot 10^{5}$ & 2.4 & 35 \\
5 & $5.2 \cdot 10^{5}$ & 2.1 & 16.2 \\
7 & $12 \cdot 10^{5}$ & 2.0 & 10.9 \\
10 & $42 \cdot 10^{5}$ & 1.8 & 6.5
\end{tabular}

Table 1: Simulation results for hopping at the Fermi level. Data for $\langle\mathrm{R}>/ \mathrm{a}$ nefer to $\mathrm{I}=25 \mathrm{~K}$.

The fact that $\langle R\rangle$ considerably exceeds the lattice parameter a, explains why we can recover the analytic results, which have originally been worked out for a much more complicated spatial array of hopping sites ( 3 ), by confining the simulations to a simple cubic lattice.

Also shown in the insert in figure 1 is the high temperature activation energy $\mathrm{E}_{\mathrm{a}}$ vs the hopping parameter $2 \alpha \mathrm{a}$. It is easily verified that it should be given by $E_{a}=\left(N_{F} a^{3} p\right)^{-1}$ where $p$ is the number of sites which on average a particle located a given site can jump to. Since $\lim _{\rightarrow \infty} i(T) \propto p \exp (-2 \alpha a), p$ is obtained by extrapolating the $\log i_{\infty} \propto \mathrm{T}^{-1}$ region to $\mathrm{T} \rightarrow \infty$. Notice that our data for $\mathrm{E}_{\mathrm{a}}$ can very well be fitted by using the $p$ values from table 1 .

Apsley and Hughes (7) have predicted the conductivity behavior as a function of electric field in the low temperature regime. The results of our simulations shown in figure 2 demonstrate excellent agreement with their predictions. Concequently, the entire simplified analytic model for hopping at the Eermi level agrees with our computer experiment. Even the magnitude of the current is in accord with theory when we normalize it to our empirical jump frequency. 


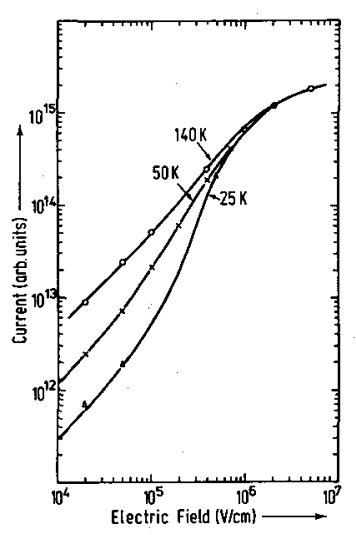

Fig.2: Field dependence of the current for $\alpha a=3$ and various $T$. Solid lines are theoretical (7).

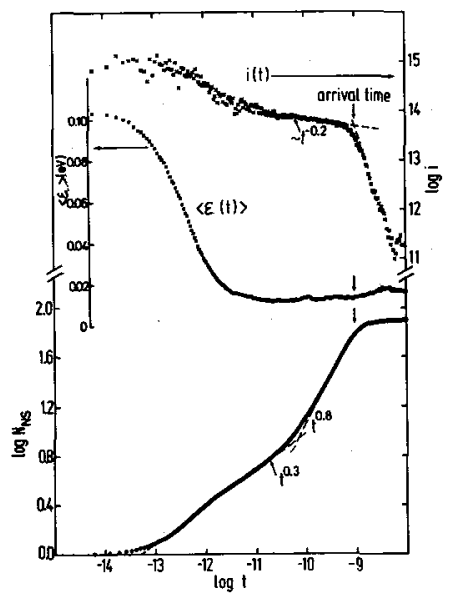

Fig.3: $\log i(t)$, mean energy $\left\langle\varepsilon(t)>\right.$ and $\log N_{N S}$ vs logt. The simulation parameters are $\mathrm{T}=25 \mathrm{~K}, \mathrm{~F}=2 \cdot 10^{5}$ $\mathrm{Vcm}^{-1}, \gamma a=3$ and $a=$ $10^{-7} \mathrm{~cm}$.
One final point is of interest. The simulations allow us to examine the dynamics of relaxation to the quasi equilibrium hopping at the Fermi level. In figure 3 we show the log $i$ vs $\log t$, $\log \langle\varepsilon\rangle$ vs $\log t$ and finally $\log N_{N S}$ vs $\log t$ where $\langle\varepsilon\rangle$ is the average energy of the hopping particles, and $\mathrm{N}_{N S}$ is the number of new sites a particle has visited after a given time $t$. As stated earlier, we start our particles off with a population proportional to the density of states. One sees that the energy relaxation to the equilibrium value is very fast, occurring after approximately 10 jumps. Within this time regime the current decays in a power-law fashion yielding a straight line with slope $\alpha_{1}-1$ when plotted on a logt vs logt scale indicating that transport is dispersive ( 8$)$. However, even after $\langle\varepsilon(t)\rangle$ has become constant, $i(t)$ continues to decrease as $i(t) \sim$ $t^{\alpha_{2}-1}$ with $\alpha_{2}>\alpha_{1}$. This signals existence of a second dispersive regime at low temperature. It is also seen the $\log \mathrm{N}_{\mathrm{NS}}$ vs $\log \mathrm{t}-\mathrm{plot}$ which shows two linear segments with slopes $\alpha_{1}<\alpha_{2}<1$. The magnitude of $\alpha_{2}$ decreases with decreasing T. The second dispersion obviously is not due to the energy relaxation tem but is a result of the inherent disorder arising from the inclusion of all possible hops. At low temperature more than 100 new sites visited are needed even in this simple system before the true d.c. conductivity is achieved. For the parameters used to calculate the data of fig. 3 this figure even exceeds the total number of new sites a particle visits before being collected at the absorbing boundary which terminates the simulation volume. Only for $\mathrm{T}>50 \mathrm{~K}$ true thermodynamic equilibrium is attained within a time less than the carrier transit time through the sample. This suggests that perhaps one should study the a.c. conductivity for Fermi level hopping as well as the d.c. conductivity. Perhaps some of the discrepencies between the experimental results and simple theory may be revealed.

In conclusion, we have simulated hopping at the Fermi level in a cubic lattice and show remarkably good agreement with simple theories. We show the high temperature saturation predicted by Movaghar and Schirmacher (3) including an activation energy which has a particularly simple interpretation.

Supported in part by the National Science Foundation under grant DMR 790023 and NATO grant (SA-2-05B (1953)/870( 80)AG). 


\section{References}

1 MOTT N.F., Phil.Mag. 19 (1969) 835; and MOTT N.F. and DAVIS E.A., Electronic Processes in Non-crystalline Materials, 2nd ed. Clarendon Press, Oxford (1978)

2 ROBERTS G.G., APSLEY N., MUNN R.W., Phys.Repts. 60 (1980) 59

3 MOVAGHAR.B. and SCHIRMACHER W., J.Phys.C., Solid State 14 (1981) 859

4 MARSHALL J.M., Phil.Mag.B 38 (1978) 335

5 SCHÖNHERR G., BÄSSLER H. and SILVER M., Phil.Mag.B, in press

6 SCHÖNHERR G., EIERMANN R., BÄSSLER H. and SILVER M., Chem.Phys. 52 (1980) 287

7 APSLEY N. and HUGHES H.P., Phil.Mag.B 31 (1975) 1327

8 SCHER H. and MONTROLL E.W., Phys.Rev.B. 12 (1975) 2455 